\title{
PROSTHETIC REHABILITATION OF A PATIENT WITH OCULAR DEFECT- A CASE REPORT
}

Jaswinder Kaur

Reader, Department of Prosthodontics, Baba Jaswant Singh Dental College, Hospital and Research Institute, Punjab, India

\begin{abstract}
(1)
ABSTRACT
The disfigurement associated with the loss of an eye may result in significant physical and emotional problems. The article describes the successful rehabilitation of a patient with missing eye with a custom made ocular prosthesis. This allows the patient to be accepted in society without being a victim of unwanted sympathy.
\end{abstract}

Keywords : Ocular, Prosthesis, Enucleation, Eye Socket, Custom made

\section{INTRODUCTION}

"It is the God given right of every human being to appear human".

\section{- Ernest L. DaBreo}

Eye is a vital organ not only in terms of vision but also being an important component of the facial expression. The ocular losses are embarrassing to the bearer because they commit the face which has the essential organs for the human relationship. Such patients often discover that they are regarded as social inferiors. Opportunities available to the non disfigured are often denied to them; so social participation, interpersonal relationships and a variety of cultural activities are affected or altered in some way. ${ }^{1}$ Maxillofacial prosthetic services rehabilitate individuals who suffer anatomical compromise due to congenital disorders, trauma and oral/facial malignancies. Ocular prosthesis is a maxillofacial prosthesis that artificially replaces an eye missing as a result of

Corresponding Author: Jaswinder Kaur E-mail: manjitkiran@yahoo.co.in Received: $29^{\text {th }}$ November 2016 Accepted: $3^{\text {rd }}$ March 2017 Online: $20^{\text {th }}$ May 2017 trauma, surgery, or congenital absence. The prosthesis does not replace missing eyelids or adjacent skin, mucosa or muscle. ${ }^{2}$ Trauma can be considered as the most important cause of unilateral loss of vision in developing countries. ${ }^{3}$ Patients requiring treatment with custom ocular proethesis are those who have lost ocular structure through orbital evisceration or orbital enucleation. ${ }^{4}$ Ocular prosthesis can be either readymade or custom made. A prosthesis which adapts well, improves the psychological state of the patient and also increases the patient's confidence level and the esthetic value. ${ }^{5}$

\section{CASE REPORT}

A 80 year old male patient reported in department of Prosthodontics with a chief complaint of missing eye (Figure 1).

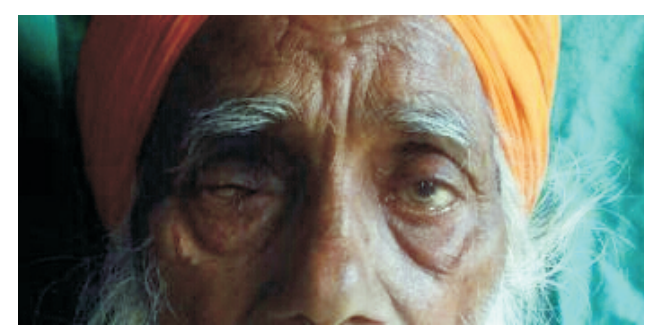

Figure 1

Examination revealed well healed socket with healthy mucosa. History revealed removal of the eye after traumatic injury 10 years back.

Patient was seated in an upright position with head supported. Primary impression was made with fluid viscosity 
irreversible hydrocolloid impression material loaded in a syringe ( Figure 2).

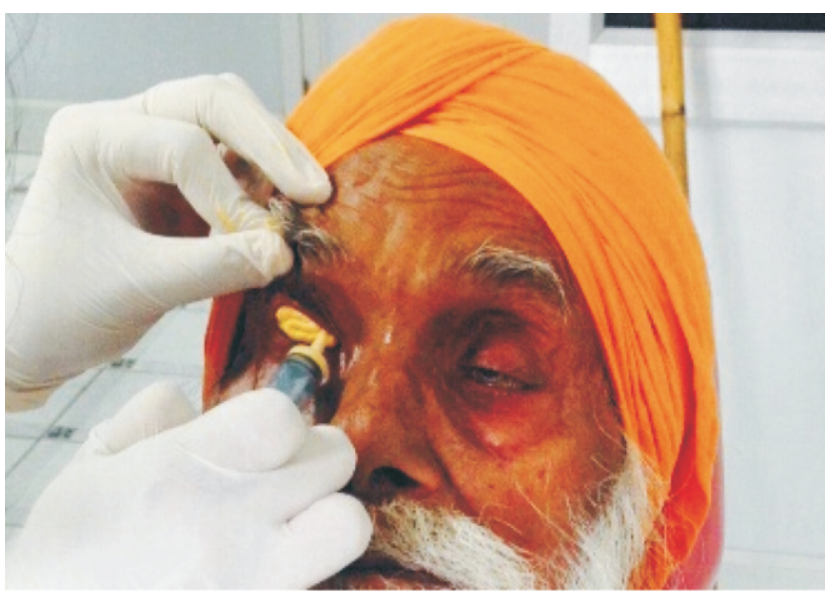

Figure 2

After complete set of impression material, it was removed from the eye, poured to obtain primary cast. Special tray was fabricated with autopolymerising acrylic resin. Tray was tried in the socket and adjusted. An opening was created in the center of the tray to fit the syringe. Outer surface of the socket was coated with Vaseline. Light body polyvinyl siloxane impression material was loaded in the syringe and injected into the socket through syringe tray assembly. Patient was seated in erect position with head tilted backwards at 45 degree. Patient was instructed to perform all the eye movements while the material sets. This made impression material flow properly and record accurately the anatomic details. After complete set of impression material, assembly was removed (Figure3). Impression was checked for air bubbles and was compared with the socket to see that all areas correspond. Syringe was disengaged and replaced with a wax sprue.( Figure 4)

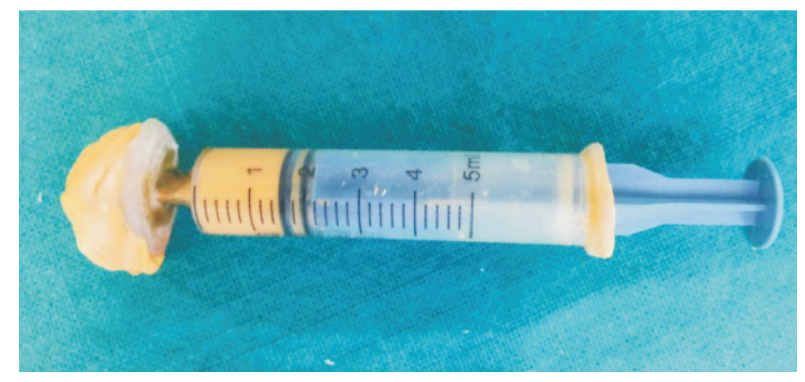

Figure 3

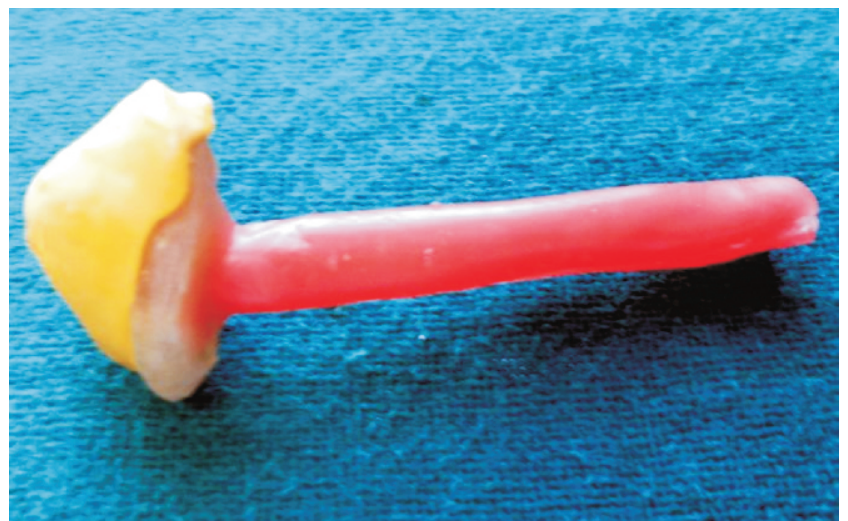

Figure 4

Impression was used to pour a 2 piece split cast mould. After the stone sets, two parts of split cast were separated and impression along with the tray was removed. Wax was removed. Split cast assembly was assembled and molten wax was poured into the mould through the channel created by removal of wax sprue to obtain the scleral wax pattern. Wax pattern was retrieved and polished. Wax pattern was tried into the patient's socket (Figure 5) and was modified to achieve

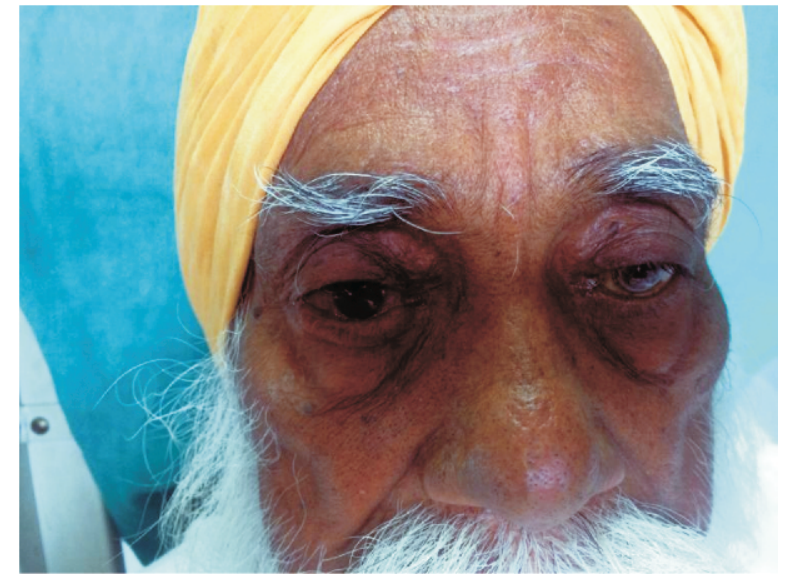

Figure 5

satisfactory contours of eyelids. For determining position of the iris, midline of patient's face was marked. Patient was asked to look straight. Distance from midline to center of the natural eye's iris was measured and the same distance was marked to the defect side and engraved into the wax pattern. Wax pattern was taken out; wax was scooped from the 
marked area. Iris was obtained by trimming and modifying a commercially available stock eye with resembling features and positioned with edges properly blending with the wax pattern.

Self cure acrylic resin handle was attached to the iris with glue and wax pattern was invested in a flask. Dewaxing was done. A thin layer of heat cure clear acrylic resin was spread in and around iris and characterization was done to achieve appearance of patient's natural eye. Silk fibers were added to stimulate vasculature. Mold was packed with heat cure tooth colored acrylic resin of matching shade and curing was done. Prosthesis was removed, finished and polished (Figure 6).

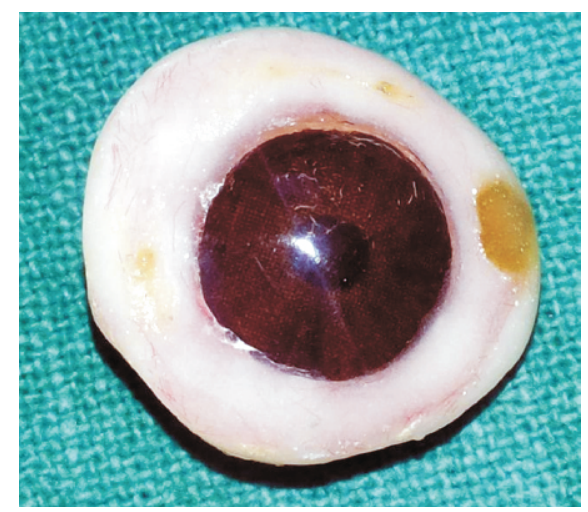

Figure 6

Disinfected, rinsed with sterile saline solution and was inserted in the patient's eye socket (Figure7).

Patient was instructed regarding use and care of prosthesis and insertion \& removal of prosthesis. Patient was recalled for follow up after one day, 1 week, 1 month and 3 months.

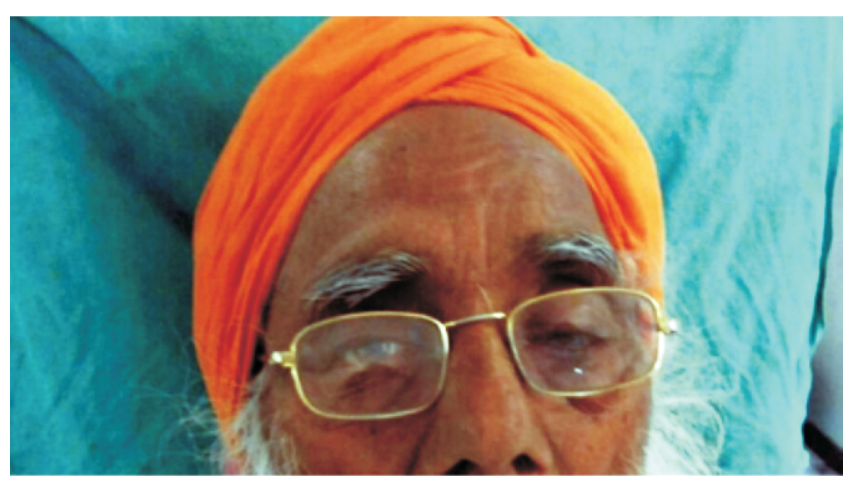

Figure 7

\section{DISCUSSION}

Surgical procedures in the removal of eye can be classified into 3 general categories; evisceration, enucleation and exenteration. Eviscerationn involves removing the contents of the globe, but leaving the sclera and sometimes cornea in place. Enucleation is the surgical removal of the eyeball after the eye muscles and optic nerve have been severed. Excentation is the en block removal of the entire orbit usually involving partial or total removal of the eyelids. $^{6}$

The art of making artificial eyes has been known to man from the days of the early Egyptian and the Peruvian Indian but not until the time of World War II and the development of the refined plastics which came then, has there been the option for a satisfactory esthetic ocular prosthesis. ' Goal of any ocular prosthetic procedure is to return the patient to society with a normal appearance. ${ }^{8}$ Stock prosthesis require elaborate, time consuming procedures and also lack close fit therefore cannot stimulate eye movement. A properly fitted and acceptable custom ocular prosthesis retains the shape of the defect socket, prevents collapse or loss of shape of the lids, provides proper muscular action of the lids, prevents accumulation of the fluid in the cavity, maintains palpebral opening similar to the natural eye, mimics the coloration and the proportions of the natural eye and has a glaze similar to the natural eye. ${ }^{4}$ Esthetic and functional outcome of custom prosthesis is always superior to the stock prosthesis

\section{CONCLUSION}

Although ocular prosthesis doesn't provide the vision but makes person more acceptable to the society and help in developing their personality. Custom made ocular prosthesis are more esthetic and provide precise results. The method has provided good results from patient esthetics, acceptance and satisfaction point of view. 


\section{BIBLIOGRAPHY}

1. Chalian, VA, Drane JB and Standish SM. Maxillofacial prosthetics: Multidisciplinary practice. Wilkins: Baltimore 294-304 1971

2. The Glossary Of Prosthodontic Terms J Prosthet Dent. 2005; 94(1):10-92

3. Goiato MC. Aesthetic and functional ocular rehabilitation Oral Oncology 2005; 41:162-164

4. Taylor TD. Clinical Maxillofacial Prosthetics. Quintessence publishing Co. 2000 233-276
5. CainJR Custom ocular prosthesis. J Prosthet Dent. 1982;48: 690-694

6. Perman KI, Baylis HI. Evisceration, enucleation and excenteration. Otolaryngol Clin North Am 1988;21:171-82.

7. Welden RB, Niiranen JV. Ocular prosthesis J Prosthet Dent. 1956; 6(2): 272-278.

8. BeumerJ Curtis TA and Firtell DN Maxillofacial rehabilitation: Prosthodontics and surgical considerations. CV Mosby: St. Louis 364-371, 1979. 